\title{
Ostentation or Visibility: A Cultural Study of Consumption of Cosmetics by Iranian Young Women
}

\section{Hossein Hassani}

PhD Candidate in Communication, University of Tehran

h.hassani@gmail.com

Manijeh Akhavan

MA graduate in Communication, University of Tehran akhavansanaz@yahoo.com

\section{Ahmad Khakiyan \\ MA graduate in Sociology, Dehaghan Azad University \\ Ehsan Shahghasemi}

PhD. in Communication, University of Tehran Shahghasemi@ut.ac.ir

\section{Zohreh Faghani}

MA graduate in Communication, University of Tehran

\section{Doi:10.5901/mjss.2015.v6n4s3p182}

\section{Abstract}

This paper studies the meanings and connotations using cosmetics among Iranian young women. A salient phenomenon in contemporary Iran is the overuse of cosmetics by women. This has culminated in raising concerns by religious figures, social critics, government authorities, and physicians. These are all happening in post-revolutionary Iran in which according to Islamic rules, women are expected not to expose their body and ornaments. Therefore, the paradox of living under Islamic laws and the will to be modern is concerned / addressed / discussed here. How, then, Iranian young women interpret their make-up, whether as ostentation, as resistance against dominant ideology, as distinction from others or as the result of new global media influence is explained in the research.

Keywords: Iran, young women, resistance, ostentation, ideology, distinction, make-up.

\section{Introduction}

The consumption of cosmetics among Iranian women has been rapidly increasing during the past decade. Although Iran is generally associated with being a religious society, this country is currently one of the biggest customers of cosmetics in the world (Shahghasemi \& Tafazzoli, 2013). Also Iran has one of the most vivid culture of cosmetic surgeries, particularly, rhinoplasty. Despite using satellite receivers is formally forbidden in Iran, official statistics say that between 50 percent to 70 percent of the Iranian households own satellite dishes. The growth of the Internet in Iran also has been phenomenal.

On the other hand, although Iranian broadcasting tries to reduce the problem to a merely psychological disorder, gives advice in numerous (often religious) ways on the harmfulness of such behavior, and concludes that young girls should be "prohibited" from make-up; it seems that this is not the case and we have to approach the problem in a more scientifically interpretable way and see if there are other dimensions to be explored; for example, if we recognize face as the aesthetically most significant part of the body, then, as Simmel (1901) puts it, the unity of soul expressions and the manifestation of inner drives best appear in the face; that is why, he argues, face becomes an incomparable and so 
frequently used object in fine arts.

Or, with a perspective of social cognition science, the face is generally the first thing that comes to the mind when one's name is mentioned. The human's mind can perceive faces and it is particularly impressive when we put it in the context of the many different social inferences we perform, as well as the high degree of accuracy and relatively little effort with which they are typically made. Even a short look at a person's face may produce information relevant to determining his or her emotional state, personality specifications, and identity. Face perception also supports inferences about social category membership, with insights about an individual's race, gender, and age usually easily determined from one's face (Ito, 2011).

As said above, the apparently excessive consumption of beauty products by Iranian young women makes the issue, in the contemporary social cultural context of Iran, more problematic. A "more visible" female face due to the excessive use of cosmetics overwhelmingly contradicts the Islamic teachings which underpin the political-Islamic discourse dominating the current political system of Iran, for non-self-presentation or "Hijab" (in Islamic terminology) is a fundamental tenet of Islam. In other words, Hijab accounts externally and in social terms as a signifying representative for the identity of a Muslim woman. "Hijab, either as a symbolic phenomenon or as an Islamic principle, is characteristic of Islamic societies and seen as one the most outstanding features of Islamic government" (Javid, 2009, p. 2). The objective of the present study would be to bring into light and examine this paradox, namely the emphasis on the "absence" of female face in society by the dominant political system, and again the emphasis on all the more active and clear "presence" of women in social activities. Put it another way, the study aims at exploring the probable meanings of cosmetics consumption by Iranian women. Given the fact that women in Iranian society are not legally [and religiously] allowed to present their bodies [in simplest sense of the word, just as men can do] and that they are solely permitted to expose their face and hands [of course down the wrist], it would be of great importance to understand the meanings mediated by that exaggerated consumption of cosmetics.

It seems now that "the face" gains a huge significance and becomes the producer and representative of individuals' identity, intentions, and wanting; thus decoding the implicit and explicit meanings attached to the beauty products used by Iranian female population could be the key to understanding their demands; so, one must take into consideration how women make sense of cosmetics and view them over against the ideological system at work in schools, universities, workplaces, and mass media which call for Hijab and "invisibility"; Rather than using cosmetics and presenting body parts and its appearances. In short, the main question of our study is whether make-up could be accounted for as a kind of resistance to the dominant discourse or it could be interpreted in other way: young women are being sacrificed in that they use cosmetics conspicuously to present and expose their self in a patriarchal society.

Before we come to the main body of the study, it should be noted that the female body has generally had a central place in sociology of body or body studies (Blackman \& Featherstone, 2010). In addition to various feminist views on cosmetics consumption - for example, beside the approaches developed by Felski (2006) we can refer to works of Negrin (2002) and Holliday \& Taylor (2006) too - there are many other studies done in relation to female body from divers (often non-feminist) perspectives: cosmetic surgery (see Gimlin (2010); Davis (2002)); medical sociology (see Cockerham (2001); Annandale (Annandale, 1998)); body and consuming culture (see for example Featherstone (2007; 2010)); and psychology (see Heyes (2009); Von Soet et al. (2009); Swami et al. (2009)). There are however some studies done by Iranian scholars: from psychological point of view (Seyed Toutunchi et al. (2007); Ghalehbandi and Afkham Ebrahimi (2004); Mousavizadeh et al. (2009)) and from sociological and cultural-studies perspective (Keyvan Ara et al. (2010); Zokaei and Farzaneh (2008); Movahed et al. (2010)). What, however, makes our study distinct is that it tries - by focusing on make-up as a cultural resistance and the conspicuous way of cosmetics consuming - to understand the meanings of cosmetics consumption in a specific social cultural context.

\section{Conceptual Framework}

As we said before, the concept of resistance in cultural studies, and the concept of distinction in Bourdieu's work inform our theoretical our theoretical approach in this study. These frameworks go beyond the already established academic disciplines in explaining why people do what they do.

\subsection{Resistance}

If one considers the standpoints and discussions on ideology and its functions (Eagleton, 2002; Williams, 1977; Rush, 1992) he or she will find that ideology aims to prescribe a particular discourse and a preferred picture of the world, to reproduce the social order and relations, to construct specific identities and to render cultural membership. Ideology is not 
exclusively giving a world-view, but it prescribes a particular one; making use of signs and meanings, it attempts to reproduce power relations and feeding the existing power. Signs and codes are then of great importance here. A paramount code is the code of clothing and making-up. This code means the sign system of clothing and making-up. John Fiske (1990) interprets the act of wearing high-heel shoes (which is a sign within the clothing codes) as a sign serving the patriarchal ideology because it would have as its consequences some functions, namely to increase the attractiveness of woman, to expose this attractiveness to men, to submit to men and hence to reproduce patriarchal meanings. Utilizing Althusserian conception of contemplation to explain this sign (wearing high-heel shoes), he argues that by doing so women make themselves the object of patriarchal system contemplation and submit to it by accepting it. But all ideologies are not always accepted by all people; they may, according to Gramci, be confronted by the resistance of individuals and groups. Clothing and making-up, because of its objective and external manifestation, could be recognized as a main domain in which people can resist to the domination of ideologies. There are certainly different kinds of resistance in different countries depending on the ideology or even ideologies at work. For example, making-up and particular clothing styles, in a society dominated by Islam and Islamic ideology could be an expression of resistance to the system, for the system emphasizes the prohibition of making-up and unorthodox clothing. A more universal resistance through making-up and clothing could form against the ideology of consumer capitalism. Another noteworthy point in this regard is that resistance to the Islamic ideology and its emphasis on Hijab may transform to a kind of submission to the patriarchal ideology and capitalism which are observable in specific classes in Iran.

\subsection{Distinction}

Bourdieu uses the term to explicate a situation in which groups of people become culturally so characterized that they become distinct. Such distinctions could be a focal point of symbolic conflict in which every group attempts to prove its superiority over others. Giving attention to the concept of class, Bourdieu uses it to refer to class struggles. It seems clear that one could use it to refer to the struggles of those groups with different standpoints too. The struggle to be distinct is a domain in which habituses arise and group members form their identity with signs and codes that indicate their superiority. Such signs and features reflect, in turn, how the individual finds her / his place. Bourdieu argues that cultural consumption is a method for different stratums to distinguish themselves and claim for a higher place among others. The dominant classes attempt to make their interests, preferences, tastes, and lifestyle to the most valuable and desiring by cultural production and consumption. Their hegemonic class dignity is preserved to the extent that their values, aesthetics, and judgments become dominant (Seidman, 2008). As it is clear in Bourdieu's work, make-up and clothing styles could be as tools for representing distinction and peculiarities because of their being the most objective and ubiquitous aspect of lifestyle and beliefs. The distinction brought about by the kind of make-up could be a signifier of individual desire to transcend from the religious and traditional world to the social classes with specific characteristics. Distinction is also a key concept in Simmel's debate on the life in metropolis and fashion. In his essay on "Metropolis and Mental Life" uniqueness and specificity is of great importance for personal substance. He also recognizes fashion as a tool to be like fellows and simultaneously to differ from the non-fellows (Vandenberghe, 2009).

\section{Methodology}

Since our research is concerned with the understanding of how Iranian women, as active social agents, interpret their make-up in a specific context (Blaikie, 2000) a qualitative method has been used. Based on what Lindlof and Taylor (2011) call interview, we tried to find out first hand perception of Iranian women about their makeup. An open ended, short questionnaire was designed and young women were invited to answer questions.

\subsection{Sampling}

Our sample is composed of interviews with women from different social classes. This approach helped us to avoid becoming biased towards a special social group. This type of sampling also helped us to get more diverse responses.

Our sample composed of young women who had make-up and accepted to participate in our study; 37 women participated in this study and their age range was 18-35. Before interviewing, the researcher provided the interviewees with some insights into the structure of questions and purpose and procedure of the study.

This helped them to be sure their anonymity would be preserved. Therefore, in some cases and upon request from participants, we used pseudonyms.

The process of data collection took two months and generally every interview took about one hour. The interviews 
were carried out in public places like parks, colleges etc.

\title{
3.2 Interviews analysis
}

Although preoccupation with the simple and so-called lay activity of making-up originates, in the eyes of some people, from specific causes such as being more attractive, drawing others' attention, lacking enough self-confidence and the like, a trained researcher can discover other aspects of the phenomenon and pose the question: do women make-up just to cover their facial flaws? Or, to put it another way, do they resort to cosmetics just to calm their psychological, subjective anxieties down? Examining the causes of making-up, our study endeavors to shed light on the attitudes people have towards women with make-up and those who do not use it. One important issue in our study is also the way women consider themselves as having right over their body.

\section{Findings}

Why do women make-up? This is a question we can approach to by analyzing the interviews with women. They argue that there are some determining factors such as religious principles dominating society, being affected by Hollywood actresses through movies and satellite TVs, maintaining social status among family members, colleagues, classmates, and friends, pretending to belong to a specific social class, and resisting the mainstream ideology; Each reason will be discussed in following sections.

\subsection{Making-up caused by religious principals}

Our results show that one of the most important reasons why Iranian women tend to consume cosmetics in an unusual way is the restrictions imposed by dress codes on them. Most of the female interviewees in this study think that Hijab covers feminine beauties:

\author{
Maryam, 26, BA \\ If I was allowed not to have Hijab, I would not use cosmetics; when I see a European woman who goes to work or \\ college with no make-up, I feel hopeless.
}

Nasrin, 30, BA

If the people around us, especially men, were a little bit fair, they would have given us the right to make-up. As we have

to put on head-coverings and this negatively affect our beauty, we have to present our beauty in other ways. to their faces.

Iranian girls and women, in fact, claim that having to have Hijab compels them to pay attention in an obsessive way

Soraya, 27, housewife

Because of the obligatory Hijab, Iranian women cannot be proud of their beauty and this is why I, as a woman, have to pay special attention to my face which is the only part of my body I am allowed to expose. My face is at the same time surrounded by a dark cloth and thus has no attraction; it is then fair that we make-up.

\section{Parisa, 28, PhD student}

I think it is very obvious and clear that we are deprived of a basic right [...] we are not permitted to go out without Hijab, and hence we must at least have the right not to be interrogated about making-up. They shouldn't command us what to do and what not to do.

Since having Hijab is obligatory in Iran, the face is the only part of the body which can be exposed and hence it becomes seriously the object of manipulation by Iranian women. Perhaps this is the main reason why there is a strong tendency to make-up among Iranian women. We should not also forget that although we did our best to avoid bias, there are still many women who choose Hijab for other reasons like being more immune to sexual harassment in public places or follow the Islamic principles.

\subsection{Maintaining social status among friends and colleagues}

In addition to seeing their faces as the locus of representation and re-presentation, some women believe that they have 
to wear make-up since in the Iranian contemporary society it is not possible to take a high status position without having proper make-up.

Leyla, 30, M.A.

If you have no make-up, other people wouldn't bother themselves to respond hello [...] when I [without make-up] go somewhere, say, shopping centers, people's behavior to me is completely different from the time when I appear in society with make-up. This proves the fact that if women want to participate in social events they have to make-up.

Leyla concludes that the social status of today's woman depends to a large extent on how they appear in social gatherings; if they make-up aptly, strangers would recognize her as a member of upper class.

\section{Katayoun, 24, BA}

I have been forced, for some reasons, to change my job; and every time I was applying for the new one I asked my sister to make-up for me. Of course I can do it by myself but I do it in a simple way which is not as attractive as my sister do. I can say that the make-up my sister does on my face is an important reason I have gotten previous jobs.

Shahnaz, 33, B.A.

My profession [in cinema industry] compels me to be up-to-date. Though I am not for the moment in direct relations with famous actors, but I have many plans for future and one has to make-up if she wants to be outstanding. You have to keep up with others, especially in cinema, to be able to progress.

Mina, 25, M.A.

I don't think [Iranian] men really believe in what they say about make-up. They say women should not make-up, but they like those women who do... Just go one day shopping or to work while wearing make-up and on the other day without it. You would simply see that you are more respectful and lovely on the day with make-up look.

Parvin, 25, high school graduate

Making-up is nowadays an important part of women lives. This was not the case in the past, for all women were housewives. Today we consist, a significant part of active citizens in the society and we have to go out every day to communicate with others; thus we have to be tidy, in order, and beautiful. Seen from this perspective, our make-ups would not perhaps be so strange; it would be like any other things we do every day.

It is noticeable in respondents' statements that they think having scientific and practical skills are no longer enough, but one has to have a made-up appearance if s/he wants to have the possibility to be chosen, to be seen.

\subsection{Pretending to belong to a specific social class}

This is another reason why women tend to wear make-up. Although they do not acknowledge it directly and explicitly, we can observe it in their interviews implicitly.

Nasrin, 30, BA

Making-up helps women to be like ladies. The way a woman wears make-up reveals the nature of her family, where she lives, her authenticity and non-authenticity.

Nazanin, 18, high school graduate

I think make-up is partially supposed to change women's status, to promote their real and actual [social] place. Many of them make-up to show that they are something else; it is a good way to achieve this goal.

Maryam, 26, BA

If we look around more carefully, we would notice that there are many women from subordinate classes who put on clothes that people from superior classes put on; they pretend to belong to those classes. Make-up is also a part of clothing. The way you use it could indicate where you belong to.

Katayoun, 24, BA

I don't make-up always, and most of the time I use cosmetics in a very simple way, but today I'm going to Jordan [an expensive street in northern Tehran] and I prefer to wear a make-up corresponding to that situation.

Given the remarks mentioned in this section, we may conclude that some women make-up to pretend to belong to a higher social class. 


\subsection{Resistance to the dominant ideology}

Beside the reasons mentioned above, some of the interviewees said they regard their make-up as a way of resistance to family, government, and even men.

\section{Roxana, 19, BA}

The only way I can show my femininity is through making-up. My family, especially my father and brother, cannot ban me; the more sensitive they show to my appearance, the more interesting becomes make-up for me. I do have rights too; it shouldn't be the case that men determine everything for everybody.

\section{Shaqayeq, 29, PhD}

We want to be equal with men; Making-up intself is perhaps of no significance for me but while I am told what to wear and what not to wear by government, I am encouraged to resist it. I don't think God favors men too in this respect. Islam is, we can argue, misrepresented in Iran, for whatever the Iranian government wants to establish is later on discovered to be rooted in Islamic teachings.

Leyla, 30, M.A.

Men are no longer authorized to tell us how to behave and how to dress. The least significance of our make-up is to reveal the helplessness of men in that they cannot find a way to prevent us from making-ups we like. They wouldn't find any.

\section{Fahimeh, 28, BA}

It is not fair that men can behave in any way they like, but women are faced with so many rules [...] men think of us as helpless creatures. However, they could not have prevented us from wearing make-up shows that we, women, can do it; this is the most important point for today's women.

\section{Shahnaz, 33, B.A.}

I am a woman and this fact shouldn't prevent me from living. Although we don't have equal rights with men, we must not submit to the male domination over our bodies and appearances. I am aware of my rights and I can decide if I want to make-up.

Some women express the fact that they are resisting the male demands. This resistance is manifested in the way they make-up and is on the one hand against the dominant rules and on the other against the male friends and relatives.

\subsection{Being affected by Hollywood actresses}

Some respondents made explicit or implicit references to Hollywood actresses as their ideal type of appearance. They said how they like to be as attractive and beautiful as European and American women, a desire which wouldn't be fulfilled unless by drawing on the appearance of prominent Hollywood characters shown in movies (esp. through satellite TV series).

Nasim, 26, MA

I watch at least one Hollywood movie every week and, as a graduate student, I cannot be a passive audience. I am watching movies to be aware of the latest worldviews and approaches to all the dimensions of life. Making-up is also an important dimension of my life. I do it and I am happy I can present myself as a famous American actress does and I choose the best facial and hair models.

Parvin, 25, high school graduate

I choose the make-up style of the most famous western actresses, used in their best movies, it means that I am so highly self-confident that I can compare myself to the best of the world and imitate their way of making-up.

Mina, 24, BA

All of the young clients [She works in barbershop] who come regularly to my shop, want me to create an appearance for them similar to that of famous singers. What, therefore, encourages me to continue my job is that I see beautiful women through satellite TVs and I think their beauty drives to a large part from cosmetics and beauty surgery.

Marziyeh, 28, housewife

Satellite TV channels are really a wonderful world. My daughter and I are so dependent on satellite TVs. I try to convince my daughter to have a make-up according to teenager models which are common in western countries. For 
myself, I certainly pay attention to the make-ups used by prominent and beautiful characters in movies.

Some of the interviewees clearly stated that, after spread of Hollywood movies, one can no longer value simplicity in appearance; to be valued is to be up-to-date and an easy way to achieve this goal is to follow American and European models who appear media.

\title{
Nazanin, 18, high school graduate
}

I am a saleswoman. When I come back home at 9 p.m. there are 2 or 3 hours left for me to watch $T V$ and have a rest. I prefer to watch Fashion TVs; I record some parts of them in order to be able to review them later on to find a good model for my hairdressing and making-up. This helps me to be up to date.

In addition to movies and satellite programs Internet, some of our respondents argue, helps to orient the way of making up.

\section{Fahimeh, 28, BA}

\begin{abstract}
I have not so much time to watch satellite TV but as I am always connected to Internet, I can surf the Web all day long and get ideas from pictures put on different sites. To make-up according to pictures is much easier than drawing on your imagination or on retrieving a scene from a film or the like.
\end{abstract}

\section{Shaqayeq, 29, $P h D$}

\begin{abstract}
Although satellite TVs are of crucial effect in providing models for my make-up, Internet has been more effective, for in the latter one it is often me who determine the duration of a scene, it is me who determine when and what to be shown. As soon as I decide to choose a new model for my make-up I become connected.
\end{abstract}

Finally, another claim put forward by respondents is that every human being has the right to decide what to put one and how; they perceive making-up as a completely private matter so that even husbands, brothers, and fathers are not authorized to judge that. It is not at all interesting for women if dressing and making-up is determined by another agency other than themselves; they would, in other words, continue to make-up in the way they want in order to show the incapability of men to dominate their bodies.

\section{Conclusion}

Despite the fact that, in the Iranian society and according to Islamic teachings, it is insisted that women cover (to put it differently, hide) their beauties and bodies, and the fact that political dominant system is also trying in a sense to restrict the presence of those women with make-up look in public sphere, the tendency to make-up among young women is increasing. An interesting point here is that the meaning of make-up in different socio-cultural contexts is different. In England, for example, the "no make-up look", Fiske argues, is a strategy to incorporate the resistance of many young women to the ideological practice of painting their faces(Fiske, 1990); In Iran, on the contrary, it is the "made-up look" which constitutes the resistance to the ideological system among women, the system which forbids women to make-up because of religious reasons. Women, who recognize this as an obligation and force, attempt to be more conspicuous / outstanding in society through making use of beauty products as they like.

Make-up, like many other issues, is of different nature in Iran from its counterpart in other parts of the world. The reasons may be numerous; for example a reason why women make-up in Iran is known to be their limitation through Hijab. Since Hijab, in fact, covers a woman's hair completely she might try to recover the nullified beauty through makingup. It was mentioned in the responses as a paramount reason for making-up. Another reason was the expansion and globalization of communications and the consequent access to Western shows and movies (especially via satellite TVs) was argued to be a way of determining the make-up style. Make-up training programs presented in satellite channels are warmly welcomed by some of the Iranian women. On the other hand, they try to follow movie stars' make-up styles and imitate with them in a way that it would change their social status and would maintain, as they argue, their social place among friends and colleagues and others. The difference between the ways in which people behave toward women with make-up and without it is so noticeable that it encourages them to make-up.

Finally, the last significance reason could that make-up in Iran is that it functions as a tool of resistance to the traditional family values, to patriarchy and to the political system. Women attempt to undermine the male domination over 
their body, hence they resist with the help of conspicuous consumption of beauty products and think of it as a certain, unquestionable right. The resistance to the dominant system is here of considerable importance. During the postrevolution period (since 1979) in Iran, the way the system has been viewing the women's problems - their education and presence in society, their dressing and make-up, and the like - has changed in favor of flexibility. The global trends have also been exerting tremendous impact. The ideological systems, however, have ever tried to force women by education systems and mass media to adopt "the appropriate model"; what is, nevertheless, observed (esp. in modern cities of Iran) shows that this is not, in practice, fulfilled. The war between the discourses, in other words, is coming to an end in favor of women discourse and not the dominant one.

\section{References}

Annandale, E. (1998). The sociology of health and medicine : a critical introduction. Cambridge: Polity Press.

Blackman, L., \& Featherstone, M. (2010). Re-visioning Body \& Society. Body \& Society, 16(1), 1-5.

Blaikie, N. W. (2000). Designing social research: The logic of anticipation. Cambridge, UK ; Malden, MA: Polity Press.

Cockerham, W. C. (2001). The Blackwell companion to medical sociology. Oxford, UK ; Malden, Mass., USA: Blackwell.

Davis, K. (2002). 'A Dubious Equality': Men, women and cosmetic surgery. Body \& Society, 8(1), 49-65.

Eagleton, T. (2002). Ideology: An introduction. London: Verso.

Featherstone, M. (2007). Consumer culture and postmodernism. Los Angeles: SAGE Publications.

Featherstone, M. (2010). Body, image and affect in consumer culture. Body \& Society, 16(1), 193-221.

Felski, R. (2006). 'Because it is beautiful': New feminist perspectives on beauty. Feminist Theory, 7(2), 273-282.

Fiske, J. (1990). Introduction to communication studies. London ; New York: Routledge.

Ghaleh Bandi, M., \& Afkham Ebrahimi, A. (2004). Olgoohaye shakhsiatie motaghaziane jarahie bini. Iranian Journal of Psychiatry and Clinical Psychology, 36, 4-10.

Gimlin, D. (2010). Imagining the Other in Cosmetic Surgery. Body \& Society, 16(4), 57-76.

Heyes, C. J. (2009). Diagnosing culture: Body dysmorphic disorder and cosmetic surgery. Body \& Society, 15(4), 73-93.

Holliday, R., \& Taylor, J. S. (2006). Aesthetic surgery as false beauty. Feminist Theory, 7(2), 179-195.

Ito, T. A. (2011). Perceiving social category information from faces: Using ERPs to study person perception. In A. B. Todorov, S. T. Fiske, \& D. A. Prentice, Social neuroscience: Toward understanding the underpinnings of the social mind (pp. 85-100). Oxford; New York: Oxford University Press.

Javid, M. (2009). An Introduction to Practical and Applied Dimensions of Hijab. Tehran: Cultural and Social Research Center.

Keyvan Ara, M., Rabani, R., \& Zhianpour, M. (2010). Gheshrbandie ejtemaei va eslahe badan: Jarahie zibaei be masabehe namade paygahe ejtemaei. Quarterly Journal of Women Strategic Studies, 47, 73-93.

Lindlof, T. R., \& Taylor, B. C. (2011). Qualitative communication research methods. London: SAGE.

Mousavi Zadeh, S., Niazi Shahraki, F., Kalantar Hormozi, A., Fadaei Naieni, A., \& Nasri Lari, M. (2009). Arziabie gerayesh va angizeye bimarane zan dar jarahihaye zibaiee. Pajoohandeh, 14(6), 318-323.

Movahed, M., Ghaffari Nasab, E., \& Hosseini, M. (2010). Make up and social life of young girls. Women in Development \& Politics, 1, 79106.

Negrin, L. (2002). Cosmetic Surgery and the Eclipse of Identity. Body \& Society, 8(4), 21-42.

Rush, M. (1992). Politics and society: An introduction to political sociology. New York: Prentice Hall.

Seidman, S. (2008). Contested knowledge: Social theory today. Malden: Blackwell Publishing.

Seyed Toutunchi, S., Fakhari, A., \& Kolahi, F. (2007). Ertebate alaeme ravanshenakhti ba rezayet pas az amale rhinoplasty. Medical Journal of Tabriz University of Medical Science \& Health Service, 29(2), 71-76.

Shahghasemi, E., \& Tafazzoli, B. (2013). Scrabble the face of your opponent: Iranian blogger's endeavour to discursively undermine Ahmadi Nejad's legitimacy. Online International Journal of Arts and Humanities, 2(8), 198-207.

Simmel, G. (1901). Die ästhetische Bedeutung des Gesichts. In Simmel, Brücke und Tür: Essays des Philosophen zur Geschichte, Religion, Kunst und Gesellschaft (pp. 153-159). Stuttgart: Koehler.

Swami, V., Chamorro-Premuzic, T., Stacy, B., \& Furnham, A. (2009). Acceptance of cosmetic surgery: Personality and individual difference predictors. Body Image, 6(1), 7-13.

Vandenberghe, F. (2009). La sociologie de Georg Simmel. Repères: La Découverte .

Von Soet, T., Kvalem, I. L., Roald, H. E., \& Skolleborg, K. C. (2009). The effects of cosmetic surgery on body image, self-esteem, and psychological problems. Journal of Plastic, Reconstructive \& Aesthetic Surgery, 62(10), 1238-1244.

Williams, R. (1977). Marxism and literature. Oxford: Oxford University Press.

Zokaiee, M., \& Farzaneh, H. (2008). Zanan va farhange badan. Journal of Cultural Studies and, 11, 43-60. 